\title{
An initial analysis of software engineers' attitudes towards organizational change
}

\author{
Per Lenberg ${ }^{1}$ (D) . Lars Göran Wallgren Tengberg ${ }^{2}$. \\ Robert Feldt ${ }^{3}$
}

Published online: 16 December 2016

(C) The Author(s) 2016. This article is published with open access at Springerlink.com

\begin{abstract}
Employees' attitudes towards organizational change are a critical determinant in the change process. Researchers have therefore tried to determine what underlying concepts that affect them. These extensive efforts have resulted in the identification of several antecedents. However, no studies have been conducted in a software engineering context and the research has provided little information on the relative impact and importance of the identified concepts. In this study, we have combined results from previous social science research with results from software engineering research, and thereby identified three underlying concepts with an expected significant impact on software engineers' attitudes towards organizational change, i.e. their knowledge about the intended change outcome, their understanding of the need for change, and their feelings of participation in the change process. The result of two separate multiple regression analysis, where we used industrial questionnaire data $(\mathrm{N}=56)$, showed that the attitude concept openness to change is predicted by all three concepts, while the attitude concept readiness for change is predicted by need for change and participation. Our research provides an empirical baseline to an important area of software engineering and the result can be a starting-point for future organizational
\end{abstract}

Communicated by: Emerson Murphy-Hill

Per Lenberg

perle@chalmers.se

Lars Göran Wallgren Tengberg

larsgoran.wallgren@psy.gu.se

Robert Feldt

robert.feldt@bth.se

1 Division of Software Engineering, Chalmers University, SE-412 96 Gothenburg, Sweden

2 Department of Psychology, Gothenburg University, Gothenburg, Sweden

3 Department of Software Engineering, Blekinge Institute of Technology, Karlskrona, Sweden 
change research. In addition, the proposed model prescribes practical directions for software engineering organizations to adopt in improving employees' responses to change and, thus, increase the probability of a successful change.

Keywords Software engineering - Human aspects - Organizational change - Attitudes · Openness to change $\cdot$ Readiness for change $\cdot$ Systematic literature review $\cdot$ Behavioral software engineering $\cdot$ Social psychology

\section{Introduction}

In order to cope with a complex and changing environment, organizations seek to find new and more efficient ways to conduct their business (Platt 2007; Serour and Younessi 2006; Serour and Winder 2007; Greenwood and Hinings 1996). The capacity to manage change has become a key determinant of competitive advantage and survival (D'aveni 2010), and, therefore, industries need to adopt and utilize new processes, technologies and innovations that may enable them to achieve their goals.

Even if the importance of organizational change has been acknowledged, many of the change efforts fail to achieve their intended aims (Beer 2000). For example, a survey of over 3,000 executives reported that two thirds of the respondents indicated that their companies had failed to achieve an improvement after implementing organizational changes (Meaney and Pung 2008).

In response to the high failure rate, work and organizational researchers have sought to identify factors that increase the likelihood of successfully implementing organizational changes. The research has shown that one of the most critical factors is employees' attitude towards change (Rafferty et al. 2013; Oreg et al. 2011). An organizational change cannot be considered successful without a change in the employees' behavior (Kotter and Cohen 2002), which, according to social psychology researchers (Ajzen 2001), is controlled and predicted by attitudes.

To gain deeper knowledge of how to influence the employees' attitudes towards organizational change, researchers have tried to determine what underlying concepts that affect them. The results from these research efforts have been summarized in several comprehensive literature reviews (Choi 2011; Oreg et al. 2011; Piderit 2000; Bouckenooghe 2010). The studies reveal that approximately thirty underlying concepts so far have been identified and analyzed in various organizational contexts. Even if the research shows that the attitudes are context dependent (ten Have et al. 2016; Oreg 2006; Pettigrew et al. 2001), none of the underlying factors have, however, been explored in a software engineering organization.

The ability to conduct and cope with organizational change is especially important in software engineering organizations, where rapid changes in influential technologies, changing customer demands, and constantly evolving methodologies create a turbulent environment (Highsmith and Cockburn 2001; Nerur et al. 2005; Lenberg et al. 2015b). The employees in software engineering organizations are frequently exposed to organizational change, which is a considerable source of stress (Ferrie et al. 1995; Woodward et al. 1999). Thus, these changes need to be managed as smoothly as possible in order to maintain healthy stress levels and keep employees motivated.

Given the importance of organizational change, the significance of attitudes in the change process and the proven contextual influence on such attitudes, we think that it is high time that attitudes towards organizational change are further explored in a software engineering context. Thus, the purpose of this study is to create, verify and validate a model that predicts 
software engineers' attitude towards organizational change. We aim to identify and include concepts that are relevant for software engineering and that have a significant impact on their attitudes.

We argue that previous attitude research forms a relevant starting-point for this study in spite of that no studies have been conducted in a software engineering context. Even if software development is different from many other types of work, we find it unlikely that it would constitute a whole different type of human endeavor.

We acknowledge that existing work and organizational psychology research presents a rich description of attitude towards organizational change, but note that it provides little or no information regarding the hierarchy between the underlying concepts in terms of impact. In view of the contextual importance, and in order to identify and select factors with a significant impact on software engineers' attitudes, we conducted a literature review of organizational change in software engineering organizations. Then we combined the knowledge gained through the review with knowledge from existing attitude research (Choi 2011; Oreg et al. 2011; Piderit 2000; Bouckenooghe 2010) to compile the model.

The model was verified using industrial data collected from a department within a Swedish software development company. The department, which developed safety critical software for the global market, aimed to transfer from a project-driven development process to a product-driven development process. It also wanted to move from having temporary project development teams towards having more stationary product development teams. Thus, the intended changes affected both the organizational structure and the software development processes. The data were captured at a single occasion in the beginning of the change process and, therefore, we cannot, in this study, make any statement regarding the outcome or success of that specific change.

This present work contributes to the understanding of change in software engineering organizations by selecting and identifying three underlying concepts with a significant impact on the employees' attitudes. In addition, it adds knowledge to prior attitude research by identifying and verifying two previously unexplored underlying concepts. Furthermore, the model proposed in this study provides a baseline for future software engineering attitude research and prescribe practical directions for software engineering organizations to adopt in improving employees' responses to change.

In the next section, we give further background information regarding attitudes in general and also attitudes in relation to organizational change. Then, we present the method and results of our analysis. Finally, the result is discussed and concluded.

\section{Background and Related Research}

In the following sections, we briefly describe previous research that we have deemed relevant and that has affected our study. This includes software process improvement, work and organization psychology, behavioral software engineering, the attitude concept and, finally, attitudes in relation to organizational change.

\subsection{Software Process Improvement}

Software process improvement (SPI) models such as the Capability Maturity Model (CMM) and CMMI, and standards such as ISO's SPICE (ISO/IEC-15504 1998) focus on improving processes (Niazi et al. 2006). SPI research is motivated by the assumption that there is a direct relation between process quality and the quality of the produced software (Cugola 
and Ghezzi 1998). The aim of SPI is, thus, to increase product quality, but also to reduce time-to-market and production costs (Cugola and Ghezzi 1998).

Little attention has been paid to the effective implementation of the SPI models and standards, which has resulted in limited success for many SPI efforts (Herbsleb and Goldenson 1996; Niazi et al. 2006). Researchers have suggested that SPI may not be delivering the benefits promised because insufficient attention has been paid to the human aspects of the implementation (Baddoo and Hall 2004). In addition, a review study (Lavallée and Robillard 2012) identified developers resistance towards SPI as one of seven factors that have an impact the implementation of SPI.

\subsection{Work and Organizational Psychology}

Psychology is the study of the mind and behavior (Association 2015). Naturally, organizational psychology ${ }^{1}$ is the application of psychology in the workplace, i.e. is concerned with 'behavior in the workplace' (Muchinsky 1997).

Work and organizational psychology has been in existence for about the last century. The question of what is significant for an individual's well-being and job satisfaction has been one of the most important research areas in organizational psychology since the 1920s. In the 1920s the research concentrated on physical work conditions such as lighting, ventilation and noise level. In the beginning of the 1930s to the beginning of the 1940s, the interest in the social aspects of the work environment increased. During these years the "human relations" - movement began, with Elton Mayo (1946) as one of its main spokesmen. Today work and organizational psychology raises important questions about how to manage effectively in organizations, in particularly with the increasing number of knowledge workers whose commitment is critical to organizational success.

\subsection{Behavioral Software Engineering}

Lenberg, Feldt and Wallgren have defined the research area of Behavioral Software Engineering (BSE) as the study of cognitive, behavioral and social aspects of software engineering performed by individuals, groups or organizations (Lenberg et al. 2014). A BSE literature review (Lenberg et al. 2015a) indicated that the human aspect of software engineering is a growing area of research that has been recognized as important. However, the review also showed that there are knowledge gaps and that earlier research has been focused on a few concepts, which have been applied to a limited number of software engineering areas, and, also, that the BSE research, so far, rarely has been conducted in collaboration by researchers from both software engineering and social science.

\subsection{The Attitude Concept}

According to (Ajzen 2001), it is commonly accepted that attitude represents a summary evaluation of an object captured in dichotomous dimensions such as good-bad, harmfulbeneficial, pleasant-unpleasant and likable-dislikeable. One frequently used attitude model is the expectancy-value model (Fishbin 1972), which basically states that the overall attitude

\footnotetext{
${ }^{1}$ Also sometimes referred to as industrial and organizational psychology, occupational psychology, or work psychology.
} 
towards an object is determined by the sum of the beliefs towards the same object. Each belief is weighted by the strengths of its constituting, individual beliefs.

Furthermore, attitudes are considered an important area of research in social psychology since they predict behavior (Crano and Prislin 2006). The most prominent behavior prediction model is the theory of planned behavior (TPB) (Ajzen 1991) and, its somewhat less used predecessor, the theory of reasoned action (TRA) (Fisbein and Ajzen 1975). According to TPB, people act in accordance with their intentions and perceptions of control over the behavior while intentions in turn are influenced by attitudes towards the behavior, subjective norms and perception of behavior control. Another acclaimed theory, also closely associated with attitude change, is the cognitive dissonance theory developed by Festinger (1962) in the 1950's. The theory states that people are motivated to reduce dissonance, which can be achieved through changing their attitudes or beliefs.

Regarding the formation and change of attitudes, (Crano and Prislin 2006) state the there exists two types of process models; single or dual process models. The single process model operates automatically while the dual process operates in a controlled fashion (Gawronski and Creighton 2013). The dual process models are the most influential and an example of such is the heuristic-systematic model (HSM), which describes two depths in the processing of attitude change: systematic and heuristic (Johnson and Eagly 1989). The level of process is, to a certain extent, determined by the level of motivation and/or cognitive ability, where systematic processing occurs when individuals are motivated and have a high enough cognition to process a message, and, consequently, heuristic processing occurs when the individuals have low motivation and/or low cognitive ability to process a message. Hence, when an individual is unmotivated or unable to process a message, they will use less cognitive intensive features to form the attitudes. The individual uses what Crano and Prislin (2006) refer to as "peripheral cues" or heuristics (e.g. "Dad's usually right"), which are more related to the source than the actual message content. In the latter case, the source will play a more important part in the attitude formation. However, it should also be noted that heuristic attitudes are less stable and less likely to influence behavior, compared to those formed by systematic processing.

Furthermore, when attitudes change, Wilson et al. (2000) state that the new attitudes override the old attitudes. The old attitudes do not, however, disappear. Instead, people can simultaneously hold two different attitudes toward a given object in the same context, one attitude implicit or habitual, the other explicit, where, yet again, motivation and cognitive ability are assumed to be required to retrieve the explicit attitude.

\subsection{Organizational Change and Attitudes}

Organizational change is both the process in which an organization changes its structure, strategies, operational methods, technologies or organizational culture to affect change within the organization and also the effects of these changes on the organization (JUMA 2014).

Attitude researchers have used several different concepts in order to measure different facets of attitudes towards organizational change. According to Choi (2011), the four most commonly used concepts are: readiness for change, openness to a change, commitment to change and cynicism about an organizational change. These attitude concepts are susceptible to situational variables and may change over time as the individuals' experiences change, and they are, therefore, better conceptualized as states than as personality traits.

Since the amount of research concerning attitudes towards organizational change is substantial, researchers have tried to comprehend it by classifying it into categories. As an 
example, in a literature study, Bouckenooghe (2010) divide the research into four dualities: (1) the nature of change (episodic change or continuous change); (2) the level of change (individual level or collective level); (3) the positive versus negative focus on change (negative problem-solving or positive potential view); and (4) the research method (variance or process methods). Bouckenooghe concludes that since employees' attitudes are rooted in psychology, the majority of studies (84 \%) adopted an individual level of analysis. He also argue that even though there is a general agreement that the individual employees' attitudes and behavior are crucial in the chance process, there is an evident need for more multidimensional view of change.

Furthermore, Oreg et al. (2011) analyzed 79 quantitative studies related to organizational change published between 1948 and 2007. The researchers present a model of change recipient reactions that consists of three categories. The first category, antecedents, consists of prechange antecedents (i.e. change recipient characteristics and internal context), and change antecedents (i.e. change process, perceived benefit/harm, and change content). The second category, explicit reactions, includes variables directly related to how change recipients feel (affect), what they think (cognition), or what they intend to do (behavior) in response to the change. The third and final category, change consequences, includes more indirect, long-term effects.

The review presents approximately thirty concepts classified into the antecedent category. Overall, the most common concepts in this category were, by far, factors that considered change recipient characteristics, e.g. trait, self-efficacy and locus of control. Far less attention has been given to employees' coping styles and motives, which address the questions of how employees deal with change and why they deal with it as they do.

Finally, worth noting is also that even if the literature reviews (Choi 2011; Oreg et al. 2011; Piderit 2000; Bouckenooghe 2010) present a rich description of attitudes towards organizational change, none presents a hierarchy in term of impact between the antecedents and, also, that none of the studies included in these reviews has been conducted in a software engineering organization.

\section{Method}

We chose to use a quantitative research design with questionnaires. According to Creswell (2013), if the problem is identifying factors that influence an outcome, the utility of an intervention, or understanding the best predictors of outcomes, then a quantitative approach is preferred. Given that much qualitatively research exists on identifying which factors affect attitudes, we argue that it is also time to build more quantitative models.

Our procedure to create the model was based on the recommendations in the Traditional Measurement Development Process outlined by Viswanathan (2005). As shown in Fig. 1, our procedure included seven steps, which are detailed in the following sections.

\subsection{Identify Dependent Variables}

We chose to represent the software engineers' attitude towards organizational change using the two concepts readiness for change and openness to change for the following reasons. First, we aimed to use concepts that had already been verified in previous research, and a literature review by Myungweon (Choi 2011) identified these as two of the most frequently used. Second, the organizational change that we explored in this study was planned by the management and, according to Miller et al. (1994), openness to change is defined 

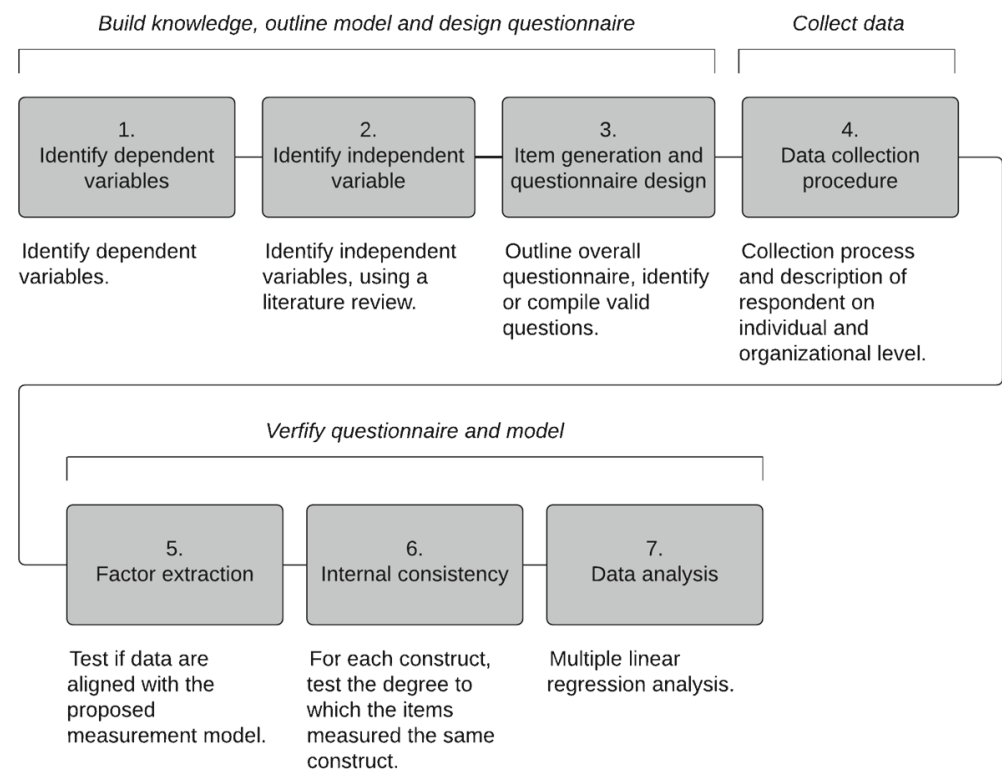

Fig. 1 Procedures used to generate the model

as an initial condition for such planned change. Third and final, since specific attitudes are a better predictor of behavior than general (Ajzen and Fishbein 1977), we wanted the questions measuring the attitudes to be directed towards the specific organizational change, not to organizational changes in general. The readiness for change and openness to change concepts met this requirement.

\subsection{Identify Independent Variables}

To identify human-oriented variables with a significant effect on organizational change in software engineering organizations, we performed a literature review. To the best of our knowledge, no such previous review has been conducted. In the next two sections we present the review method used and also the result.

\subsubsection{Review method}

Our review was based on the guidelines by Kitchenham (2004) and included the following stages: selecting data sources, selecting search string, defining research selection criteria, defining research selection process and defining data extraction and synthesis.

Selecting data sources Since we consider organizational change in software engineering to be an interdisciplinary research subject, we selected databases likely to cover both technical as well as social research; PsycINFO, Scopus and Web of Science.

Selecting search string The purpose of the search string was to capture publications related to organizational change in software engineering organizations. Therefore, we combined synonyms to 'organizational change' with synonyms to 'system engineers' (defined by Cruz et al. (2011)) with the logical AND operator. 
One main contributor to organizational changes in software engineering organizations the past fifteen years has been the introduction of agile methodologies. In order to make certain that these publications were captured, we also included synonyms to "agile transition' to the search string. The final search string looked like this: (("organizational change" $O R$ "organisational change" OR "organizational development" OR "organisational development”) OR ((agile OR kanban) AND (transition OR adaptation OR employment OR adapt $O R$ adoption $O R$ adopt $O R$ employ $O R$ implementation OR transformation $O R$ improvement))) AND ("software engineering" OR "software development" OR "agile development" OR "software engineer" OR "software developer" OR "software project").

The quality of the search strings was verified by a pilot search for three known organizational change related publication (Cohn and Ford 2003; Smits and Rilliet 2011; Mockus 2010). The search string caught all of them.

Research selection criteria In order to reduce the likelihood of bias, the study selection criteria were derived. The criteria were intended to identify those primary publications that provide direct evidence regarding the aim of the review.

Inclusion Criteria

Publication Year: We limited the search to include publications between January 2000 and July 2015. The start date was set in order to capture studies related to the agile software development approach, which has had a major influence on Software Engineering.

Publication Type: We choose to include peer-reviewed papers published both in journals and in conference proceedings.

Content: Two conditions were to be met in order for the publication to be included based on content. First, the publication shall be related to organizational change in software engineering organizations, i.e. the change had to have been studied in relation software engineering activities or to software engineers. We defined organizational change as the process in which an organization changes its structure, strategies, operational methods, technologies or organizational culture to affect change within the organization, and the effects of these changes on the organization (JUMA 2014). Second, one or several human factors related concepts shall be analyzed or considered in the study. As a general guidance when identifying such factors, we used a concept list that we defined in a previous study (Lenberg et al. 2015a).

\section{Exclusion Criteria}

Language: We limited this study to only include papers written in English.

Publication Type: We excluded papers where we could not locate a full paper version, although only one paper was affected by this exclusion criterion.

To verify the criteria two researchers independently applied them to three publications. The analysis yielded similar results.

Research selection process In total, the search identified 2506 publications. First, we applied to selection criteria to the titles and excluded papers that did not relate to change in software engineering organizations. This reduced the number of potential publications down to 196 . We then analyzed the abstract and removed papers that clearly did not consider 
any human aspects in the relation to the change, which further reduced the number down to 128. After a full review, we finally identified 107 publications.

Data extraction and synthesis We only extracted one property, i.e. human factor related concepts. As a starting point and general guidance for the extracting process we used a concept list that we defined in a previous study (Lenberg et al. 2015a).

Regarding the synthesis, to identify relevant categories we used a simplified form of thematic analysis based on the guidance of Braun and Clarke (2006). First, we familiarized ourselves with the data by read through the entire publications. Then, we generated codes.

Table 1 Human factor related concepts affecting change outcome

\begin{tabular}{|c|c|c|}
\hline Human aspects & No of publications & Publications \\
\hline Management & 18 & $\begin{array}{l}\text { (Angeline and Sudha 2015 ; Gandomani et al. 2014; } \\
\text { Gandomani et al. 2014a; Nikitina et al. 2012; Hajjdiab } \\
\text { et al. 2012; Smits and Rilliet 2011; Mathiassen et al. 2005; } \\
\text { Schatz and Abdelshafi 2005; Kautz and Nielsen 2004; Cao } \\
\text { et al. 2009; Cohn and Ford 2003; Lenberg et al. 2015b; Nerur } \\
\text { et al. 2005; Gandomani et al. 2013; Gannon 2013; Livermore } \\
\text { 2007; Boehm and Turner 2005; Ghani and Bello 2015) }\end{array}$ \\
\hline
\end{tabular}

Need for change

14

Knowledge

Participation

11

Organizational culture

10

Communication

Motivation

Commitment

Trust

Miscellaneous

(Gandomani et al. 2015; Gandomani et al. 2014b; Hutchinson et al. 2014; Gandomani et al. 2014; Gandomani et al. 2014a; Nikitina and Kajko-Mattsson 2011; Serour and Winder 2007; Serour and Henderson-Sellers 2005; Lenberg et al. 2015b; Little 2003; Duka 2013; Seffernick 2007; Boehm and Turner 2005; Ghani and Bello 2015)

(Gandomani et al. 2014b; Hutchinson et al. 2014; Gandomani et al. 2014; Gandomani et al. 2014a; 2013; Nikitina et al. 2012; Nikitina and Kajko-Mattsson 2011; Savolainen et al. 2010; Chan and Thong 2009; Duka 2013; Kim and Ryoo 2012; Hayes and Richardson 2008; Livermore 2007)

(Gandomani et al. 2015; Gandomani et al. 2014; Gandomani et al. 2014a; Nikitina et al. 2012; Nikitina and Kajko-Mattsson 2011; Serour and Winder 2007; Serour and Henderson-Sellers 2005; Kautz and Nielsen 2004; Gandomani et al. 2013; Duka 2013; Kouzari et al. 2015)

(Rodríguez et al. 2013; Escobar-Sarmiento and LinaresVasquez 2012; Nikitina et al. 2012; Smits and Rilliet 2011; Mathiassen et al. 2005; Cao et al. 2009; Nerur et al. 2005; Cestari Silva and Goldman 2014; Rosenberg 2015)

(Nikitina et al. 2012; Piri et al. 2012; Conboy et al. 2010; Lenberg et al. 2015b; Chan and Thong 2009; Hui 2013; Kouzari et al. 2015)

(Gandomani et al. 2015; Gandomani et al. 2014b; Prokhorenko 2012; Savolainen et al. 2010; Cestari Silva and Goldman 2014)

(Gandomani et al. 2015; Hutchinson et al. 2014; EscobarSarmiento and Linares-Vasquez 2012; Mathiassen et al. 2005)

(Piri et al. 2012; Nerur et al. 2005)

(Parizi et al. 2014; Sato et al. 2013; Gandomani et al. 2013; Noordeloos et al. 2012; Mockus 2010; Li et al. 2010; Qumer and Henderson-Sellers 2008; Nelson et al. 2009; Seffernick 2007; Olsson et al. 2012; Sato et al. 2013; Thomas et al. 2011; Iivari and Huisman 2007) 
A code marked a sentence(s) or a key word(s) that appeared to be related to a human factors concept. The codes were then grouped in a simplified thematic map (Cruzes and Dyba 2011). Finally, we categorized the codes into themes using the thematic map as well as surrounding information. In addition, we extracted the frequency of the theme among the included publication. The result is presented in Table 1.

\subsubsection{Review Result}

As shown in the Table 1, the review identified management as the most frequently occurring human-oriented concept. However, its definition was rather broad and diverse, meaning that it referred to both the leadership style of the individual manager but also to the commitment, knowledge and support from management in general. We did not find any appropriate way to operationalize such a diverse factor without jeopardizing the validity and reliability of the measurement and, consequently, we decided not to include it into our model.

Apart from management, the most frequently considered concepts, each included in more than ten publications, were knowledge, need for change and participation. Knowledge relates to the software engineer's understanding about the outcome of the planned change. If he/she has sufficient insights in order to determine how it will affect the company, but also how it will affect his/hers everyday work. In addition, this concept also relates to if the software engineer has previous experience of the change outcome. The second concept (need for change) describes if the employee understands why the change is necessary, i.e. to the reasons behind the initiation of the change. Does the software engineer feel that the organization needs to change, or does he/she think that everything is working quite well? The third concept (participation) relates to the software engineer's feeling of influence over the change process.

Previous attitude research has identified participation(Choi 2011; Oreg et al. 2011; Piderit 2000; Bouckenooghe 2010) as an antecedent to attitude towards organizational change. It has, however, not been explored in a software engineering context. The relation between the two other potential concepts, i.e. knowledge and need for change, and attitude towards organizational change has not previously been explored in any context. Even if their direct relation to attitudes has not been studied, we made the assessment that they, or at least concepts with similar meaning, have previously been used in organizational change theories.

Rendahl and Hart (1996) have proposed a theoretical model claiming that an effective organizational change is the sum of the three concepts: (1) that the employees understand the causes of the change, (2) that the employees accepts the proposed solution, and (3) that there is quality in the solution. Our hypothesis is that the need for change concept in our study is related to the cause of the change (1) and the knowledge concept is a prerequisite to the acceptance of the solution (2).

The need for change concept is, also, related to the first step in Kotter's (Kotter 1996) eight-step change process, i.e. sense of urgency. Kotter argues that the purpose of this first step is to help others see the need for change and the importance of acting immediately. By developing a sense of urgency around the need for change, you will be able to spark the initial motivation to get things moving.

Regarding knowledge, Beer et al. (1990) and Robey et al. (2002) have shown that effective training strengthens employees' commitment to change. In addition, according to Rendahl, a key component in achieving a quality solution (3) is to involve the employees in the change process, which means that it relates to the participation concept in our study. 


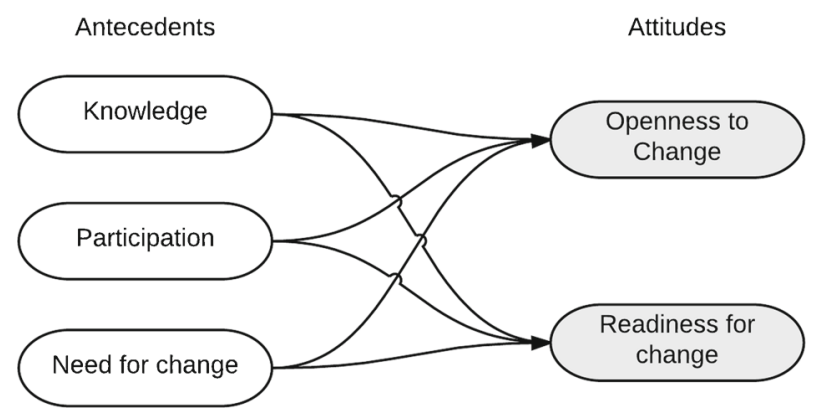

Fig. 2 Model used to predict attitudes

We also made the assessment that the three potential concepts are to be conceptualized as states, over which managers exert influence. For example, we made the assumptions that knowledge could be affected by training, that need for change could be affected by adequate information and, finally, that participation could be affected by the design of the change process.

Hence, as shown in Fig. 2, we chose to include the variables knowledge, participation, need for change, openness to change and readiness for change into our model.

\subsection{Item Generation and Questionnaire Design}

The questionnaire included two main parts. The first part included five items (or questions) related to background information about the respondent, The respondents were asked what type of work they performed (administrative or technical), if he/she was responsible for personnel or not, for how many year they had been working (0-5 years, 6-10, 11-15, > 15) and, finally, for how many years that had been working for the department ( $0-5$ years, 6$10,11-15,>15)$. The second part included items related to the five variables in the model, see Table 2. The answers to all of these questions were measured using a five-point Likert scale with the following alternatives: 1 "strongly agree", 2 "agree", 3 "neither agree nor disagree", 4 "disagree" and 5 "strongly disagree".

Openness to change was measured using an eight-item measure developed by Miller et al. (1994), and is conceptualized as willingness to accommodate and accept change, positive affect about the potential consequences of the change, and considered a necessary, initial condition for successful planned change.

Readiness for change was measured using six items proposed by Cunningham et al. (2002), and included questions reflecting the precontemplative, contemplative, preparatory, action and maintenance stages of the change model developed by Prochaska et al. (1994). The participation variable was assessed using four items developed by Wanberg and Banas (2000), which measured the extent to which employees perceived that they had input into the change. We updated these two variables and directed the question towards the specific organizational change that the company was currently undergoing, i.e. transition to team-based development.

Although we aimed to use concepts that had already been verified in previous research, we did not find any appropriate for the final two variables, i.e. knowledge and need for 
Table 2 The table shows the questions used to compile the five variables in the model. The last column indicates whether the response is to be inverted when creating the index variables

\begin{tabular}{|c|c|c|c|}
\hline Identifier & Variable & Question & Reversed \\
\hline
\end{tabular}

O1 Openness to change

$\mathrm{O} 2$

Openness to change

O3

Openness to change

O4

Openness to change

O5

Openness to change

O6

Openness to change

O7

O8

Openness to change

R1
I would consider myself to be "open" to the changes that team based development will bring to my work role.

Right now, I am somewhat resistant to the proposed changes in work teams.

I am looking forward to the changes in my work role brought about by the implementation team based development.

In light of the proposed changes regarding team based development, I am quite reluctant to consider changing the way I now do my work.

I think that the implementation of team based development will have a positive effect on how I accomplish my work.

From my perspective, the proposed changes regarding team based development will be for the better.

The proposed changes regarding team based development will be for the worse in terms of the way that I have to get my work done.

I think that the proposed changes in the work teams will have a negative effect on how I perform my role in the organization.

The programme or area in which I work functions well and does not have any aspects which need changing.

There's nothing that I really need to change about the way I do my job to be more efficient.

I've been thinking that I might want to help change something about the programme or area in which I work. I plan to be involved in changing the programme or area in which I work.

I am working hard to help improve aspects of the programme or area in which I work.

We are trying to make sure we keep changes/improvements my programme/area has made. 
Table 2 (continued)

\begin{tabular}{|c|c|c|c|}
\hline Identifier & Variable & Question & Reversed \\
\hline $\mathrm{P} 1$ & Participation & $\begin{array}{l}\text { I have been able to ask questions } \\
\text { about the changes regarding team- } \\
\text { based development. }\end{array}$ & \\
\hline $\mathrm{P} 2$ & Participation & $\begin{array}{l}\text { I have been able to participate in } \\
\text { the implementation of team-based } \\
\text { development. }\end{array}$ & \\
\hline P3 & Participation & $\begin{array}{l}\text { I have some control over the } \\
\text { changes regarding team-based } \\
\text { development. }\end{array}$ & \\
\hline $\mathrm{P} 4$ & Participation & $\begin{array}{l}\text { If I wanted to, I could have input } \\
\text { into the decisions being made about } \\
\text { team based development. }\end{array}$ & \\
\hline $\mathrm{K} 1$ & Knowledge & $\begin{array}{l}\text { I have sufficient knowledge about } \\
\text { team-based development in order to } \\
\text { determine how that will affect my } \\
\text { work. }\end{array}$ & \\
\hline $\mathrm{K} 2$ & Knowledge & $\begin{array}{l}\text { I believe that I have a good knowl- } \\
\text { edge about team-based develop- } \\
\text { ment. }\end{array}$ & \\
\hline K3 & Knowledge & $\begin{array}{l}\text { I have experience in team-based } \\
\text { development. }\end{array}$ & \\
\hline K4 & Knowledge & $\begin{array}{l}\text { I can determine if my tasks are } \\
\text { suited to be performed using a } \\
\text { team-based development. }\end{array}$ & \\
\hline N1 & Need for change & $\begin{array}{l}\text { I think that this department's cur- } \\
\text { rent way-of-working is cost effec- } \\
\text { tive. }\end{array}$ & $(\mathrm{R})$ \\
\hline $\mathrm{N} 2$ & Need for change & $\begin{array}{l}\text { I think that this department devel- } \\
\text { ops systems with the appropriate } \\
\text { quality. }\end{array}$ & $(\mathrm{R})$ \\
\hline N3 & Need for change & $\begin{array}{l}\text { The documents that this department } \\
\text { delivers to the customers hold an } \\
\text { appropriate quality. }\end{array}$ & $(\mathrm{R})$ \\
\hline N4 & Need for change & $\begin{array}{l}\text { I think that this department needs to } \\
\text { change its way-of-work. }\end{array}$ & (R) \\
\hline
\end{tabular}

change. Consequently, for these, we compiled the items ourselves using the concepts definitions, which were based on information gathered in the literature review. As stated previously, the knowledge variable relates to the employees knowledge about the outcome of the change. If he/she has sufficient in-sights regarding the change in order to see how it will affect the company, but also how it will affect his/hers everyday work. This concept also holds a component related to the experience of the outcome. We used four items to capture these aspects, see Table 2.

Finally, four items were used to form the need for change variable. The first three were related to the software engineers' opinion of the departments current way-of-working and to the quality of the systems that department produced, while the forth question was more directly related to the need for change. 


\subsection{Data Collection Procedure}

The data in this current study were collected at a department within a large ( $>10000$ employees) Swedish software company that was planning to initiate an organizational change. The department, which developed safety critical software for the global market, wanted to (1) transfer from a project-driven development process to a product-driven development process, and (2) move away from having temporary project development teams towards having more stationary product development teams (see Fig. 3). These proposed changes affected the organizational structure and the software development processes.

Traditionally, the products that the department owned had, to a large extent, been developed by customer projects, i.e. projects responsible for developing, customizing and delivering the product to a single customer. A consequence of this was that the products' feature sets were determined by the needs of the current paying customers and the products therefore became tailored to the existing customers' needs, not to the needs of the potential market as a whole. In addition, the quality of the products was dependent on the projects' budget. If one project ran out of money, the product quality was affected negatively, which led to a gradual degrease in quality and made feature development increasingly more expensive.

The management wanted a transfer of power from the project managers to the product managers. Project managers are responsible for the successful delivery of a single project. They align resources, manage issues and risks, and basically coordinate all of the elements necessary to complete the delivery. The project managers can undertake to build a product, to add new features to a product, or create new versions or extensions of a product. However, after the delivery, they move on to new projects that might involve different products. The product managers, on the other hand, are responsible for the overall and ongoing success of a product. Once the project to build the product is complete and the project manager has moved on, the product manager remains to manage the product through the entire life-cycle.

Prior to the change, the project managers allocated resources and created temporary development teams for each delivery. The idea of the proposed change was to group the developers in stationary autonomous teams controlled by a product manager, who had the product's long-term goals as guidance when making operational decisions, not the goals of a single project.

The employees were working at three different sites in Sweden. Two of the sites were roughly the same size in terms of number of employees (20), while the third site was approximately half the size. The employees had different roles and responsibilities and
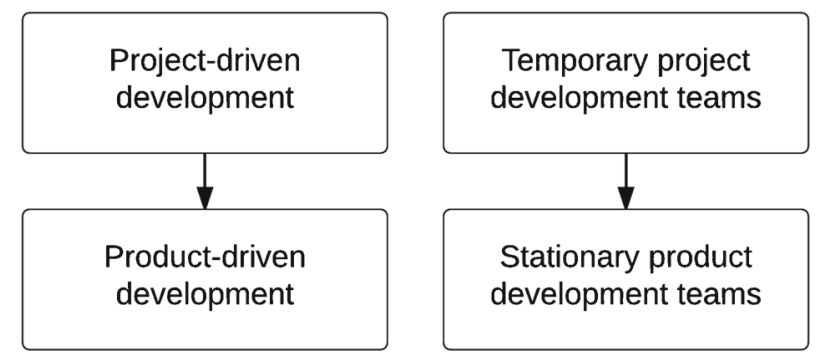

Fig. 3 Change overview 
worked as software developers, project managers, team leaders or managers. The majority of the employees ( $90 \%$ ) had a master degree in engineering, either in software engineering, engineering physics or electronics.

The questionnaires were distributed to the employees at a biweekly department meeting in October of 2014, one week after the management had announced the organizational change. Before filling out the survey the participants were informed about the purpose of the study; that it was anonymous and that it was voluntary to participate. They were also informed that the researcher would not share the raw data with other researchers nor the management, and that no attempts would be made to identify who answered which questionnaire. During the meeting, it became clear that the employees were interested in the outcome of the study and, therefore, they were promised feedback from the researcher after the survey was completed and the data was analyzed.

Of the 65 employees at the department, 57 choose to participate in the study giving a response rate of $88 \%$. Approximately one per cent of the respondents were below the age of 25 , and approximately $10 \%$ were older than 45 years. The department had been growing for the last ten years, and about $40 \%$ of the respondents had been working for the department for five year or less, while about $15 \%$ had been working there for more than 15 years. About $55 \%$ of the respondents had more than 10 years of IT work experience, $33 \%$ between six and ten years experience and $12 \%$ fewer than six years. Approximately $80 \%$ of the respondents were male.

One of the 57 submitted questionnaires was not complete and had to be discarded. Therefore, 56 participants were finally included in the survey analysis.

\subsection{Factor Extraction}

We analyzed the structure of the observations and the variables to test whether the data fit a hypothesized measurement model shown in Fig. 2. Principal components analysis (PCA) was used since the primary purpose was to identify the factors underlying our measurements (Abdi and Williams 2010). The analysis was conducted using the statistical program IBM SPSS version 22. In addition, we used varimax rotation with Kaiser normalisation and listwise deletion.

First, we made an estimate of the sampling adequacy. We recognize the sample size importance and note that several guiding rules of thumb are cited in the literature (Osborne and Costello 2004). With 56 responses, our sample size is in the lower end; however, Sapnas et al. state that, for CFA, 50 cases are adequate (Sapnas and Zeller 2002).

We also tested the sampling adequacy using the Kaiser-Meyer-Olkin measure, which return a value of .74, above the recommend suitable value of .50 (Hair et al. 2006). Bartlett's test of sphericity was used to verify that our data is suitable for reduction. The test was significant $\left(\tilde{\chi}^{2}(231)=779.23, p<.05\right)$. In addition, the diagonal values of the anti-image correlation matrix were all over .5, supporting the inclusion of each item in the analysis (Yong and Pearce 2013).

During several steps, a total of four items were eliminated (O1, R6, K4 and N4) because they did not contribute to a simple factor structure and failed to meet the minimum criterion of having a primary factor loading of .5 or above (Yong and Pearce 2013). These four items were therefore not included in the subsequent analysis.

The rotated component matrix and the communalities for the final 22 included items are presented in Table 3. For display purposes, loads less than .4 are suppressed. Descriptive data for the five variables are shown in Table 4. 
Table 3 Principal component analysis (Abdi and Williams 2010), varimax rotation with Kaiser normalisation. For display purposes, loads less than .4 are suppressed. The first column refers to the items (questions) in Table 2

\begin{tabular}{|c|c|c|c|c|c|c|}
\hline Item & $\begin{array}{l}\text { Openness } \\
\text { to } \\
\text { change }\end{array}$ & $\begin{array}{l}\text { Readiness } \\
\text { for } \\
\text { change }\end{array}$ & Knowledge & $\begin{array}{l}\text { Need for } \\
\text { change }\end{array}$ & Participation & Communality \\
\hline $\mathrm{O} 2$ & .74 & & & & & .70 \\
\hline $\mathrm{O} 3$ & .80 & & & & & .78 \\
\hline $\mathrm{O} 4$ & .58 & & & & & .55 \\
\hline O5 & .72 & & & & & .68 \\
\hline O6 & .80 & & & & & .76 \\
\hline $\mathrm{O} 7$ & .84 & & & & & .75 \\
\hline $\mathrm{O} 8$ & .85 & & & & & .82 \\
\hline $\mathrm{R} 1$ & & .51 & & & & .43 \\
\hline $\mathrm{R} 2$ & & .53 & & & & .45 \\
\hline R3 & & .80 & & & & .72 \\
\hline $\mathrm{R} 4$ & & .74 & & & & .74 \\
\hline R5 & & .64 & & & & .48 \\
\hline $\mathrm{K} 1$ & & & .81 & & & .79 \\
\hline $\mathrm{K} 2$ & & & .91 & & & .86 \\
\hline $\mathrm{K} 3$ & & & .73 & & & .72 \\
\hline N1 & & & & .54 & & .50 \\
\hline $\mathrm{N} 2$ & & & & .83 & & .73 \\
\hline N3 & & & & .70 & & .75 \\
\hline P1 & & & & & .77 & .60 \\
\hline $\mathrm{P} 2$ & & & & & .85 & .79 \\
\hline P3 & & & & & .80 & .81 \\
\hline P4 & & & & & .77 & .76 \\
\hline
\end{tabular}

\subsection{Internal Consistency}

Internal consistency is the degree to which every item measures the same concept. Cronbach's alpha, a statistical measurement calculated from the pairwise correlations between the items, was used as a lower-bound estimate of the internal consistency. The estimates, together with the mean values and standard deviations, are shown in Table 4. As can be

Table 4 The Cronbach's alpha value, mean value and standard deviation for the included variables

\begin{tabular}{lll}
\hline Variable & Cronbach Value & Mean Value (Standard Deviation) \\
\hline Openness to change & .92 & $3.71(.68)$ \\
Readiness for change & .71 & $3.70(.51)$ \\
Knowledge & .85 & $3.31(1.04)$ \\
Need for change & .68 & $2.57(.67)$ \\
Participation & .86 & $3.01(.88)$ \\
\hline
\end{tabular}


seen, the need for change variable has a somewhat lower value compared to the other variable; however, Streiner (2003) and Nunnally et al. (1967) suggested that a minimum alpha of .6 sufficed for early stage of research.

\subsection{Data Analysis}

In order to test the proposed model, multiple linear regression analysis was used with openness to change and readiness for change as dependent variable, while knowledge, need for change and participation were independent variables. The analysis was conducted using SPSS version 22 and based on the procedures outlined by Meyers et al. (2006).

Before conducting the analysis, we verified that the collected data actually could be analyzed using linear regression. A visual analysis of scatter plots for all variables indicated a linear relationship. Further, we checked the homoscedasticity and normality of residuals with the Q-Q-Plot. The plot indicated that in our multiple linear regression analysis there is no tendency in the error terms. Regarding autocorrelation, the Durbin-Watson values for the model were $d=1.73$ (openness to change) and $d=1.54$ (readiness for change). These are between the two critical values of $1.5<\mathrm{d}<2.5$ and, therefore, we can assume that there is no first order linear auto-correlation in our multiple linear regression data. Finally, the data were analyzed in order to determine the presence of multicollinearity. The variance inflation factors (O'brien 2007) were all well below three (maximum VIF was 1.13), indicating a small risk for multicollinearity.

\section{Results}

Knowledge, need for change and participation were used in two separate standard multiple linear regression analysis $(\mathrm{N}=56)$ to predict openness to change $(\mathrm{OTC})$ and readiness for change (RFC). The correlations of the variables, shown in Table 5, were overall low with a maximum value of .45 for openness to change and knowledge.

The analysis showed that the regression models for OTC and RFC are statistically significant $(\mathrm{F}(3,52)=15.25, \mathrm{p}<.001 ; \mathrm{F}(3,52)=3.82, \mathrm{p}=.015)$. The former accounts for $44 \%$ $\left(\mathrm{R}^{2}=.468\right.$, Adjusted $\left.\mathrm{R}^{2}=.437\right)$ of the variance, while the latter accounts for considerable less, $14 \%\left(\mathrm{R}^{2}=.180\right.$, Adjusted $\left.\mathrm{R}^{2}=.136\right)$. The explained variance of the OTC regression model is rather high compared to other studies in social science. This is, to a certain extent, the result of the relatively large number of participants in relation to a small number of variables; however, it also adds support that our hypothesized model is a good first-order approximation and captures important factors.

The results for the regression models are presented in Tables 6 and 7. As can be seen, knowledge is not significant in the RFC regression model, which somewhat clarifies the

Table 5 Pearson $r$ correlations of the variables. '*' means that the correlation is significant at .10 level. '**' means that the correlation is significant at .05 level

\begin{tabular}{lllll}
\hline Variable & Openness to change & Knowledge & Need for change & Participation \\
\hline Readiness for change & $.334^{* *}$ & .085 & $.314^{* *}$ & $.243^{*}$ \\
Openness to change & - & $.449 * *$ & $.247 *$ & $.339^{* *}$ \\
Knowledge & - & - & .033 & .054 \\
Need to change & - & - & - & -.108 \\
\hline
\end{tabular}


Table 6 The raw and standardized regression coefficients of the predictors together with their correlations with openness to change, their squared semi-partial correlations $\left(\mathrm{sr}^{2}\right)$ and the significance level. The dependent variable was openness to change. ' $*$ ' means that the variable is significant at .05 level

\begin{tabular}{|c|c|c|c|c|c|c|}
\hline Model & B & SE-b & Beta & Pearson $r$ & $\mathrm{sr}^{2}$ & Sig \\
\hline (Constant) & .829 & .500 & & & & .103 \\
\hline Knowledge* & .349 & .068 & .522 & .449 & .271 & .000 \\
\hline Participation* & .265 & .080 & .340 & .339 & .114 & .002 \\
\hline Need for change* & .277 & .106 & .266 & .247 & .070 & .012 \\
\hline
\end{tabular}

differences in explained variance between them. However, the need for change and the participation variables have the same order of magnitude, both in terms of their contribution to the model (Beta) and also in terms of the unique variance they explain, indexed by the squared semi-partial correlation in column $\mathrm{sr}^{2}$.

The model, which is presented in Fig. 4, indicates that knowledge has a higher impact compared to participation (only valid for openness to change), and that participation, in turn, has a higher impact compared to need for change.

\section{Discussion}

The purpose of this study was to create, verify and validate a model that predicts software engineers' attitude towards organizational change. We aimed to identify and include concepts with a significant impact on the attitudes and which were relevant for the software engineering context.

Using a literature review, we identified three potentially significant underlying concepts, i.e. the software engineers' knowledge about the intended change outcome, their understanding of the need for change, and their feelings of participation in the change process.

The result of two separate multiple regression analysis, where we used industrial data $(\mathrm{N}=56)$, showed that the attitude concept openness to change is predicted by all three concepts, while the attitude concept readiness for change is predicted by need for change and participation.

Our findings contribute to the understanding of organizational change in several ways. First of all, it adds support to previous research. It confirms that participation is an antecedent to attitude towards organizational change (Choi 2011; Oreg et al. 2011). It also provides support that the two attitude concepts we used, readiness for change and openness

Table 7 The raw and standardized regression coefficients of the predictors together with their correlations with readiness for change, their squared semi-partial correlations $\left(\mathrm{sr}^{2}\right)$ and the significance level. The dependent variable was readiness for change. '*' means that the variable is significant at .05 level

\begin{tabular}{lllllll}
\hline Model & B & SE-b & Beta & Pearson r & sr $^{2}$ & Sig \\
\hline (Constant) & 2.233 & .450 & & & & .000 \\
Knowledge & .029 & .061 & .059 & .085 & .003 & .641 \\
Participation* & .258 & .095 & .342 & .314 & .116 & .009 \\
Need for change* & .156 & .072 & .277 & .243 & .076 & .033 \\
\hline
\end{tabular}




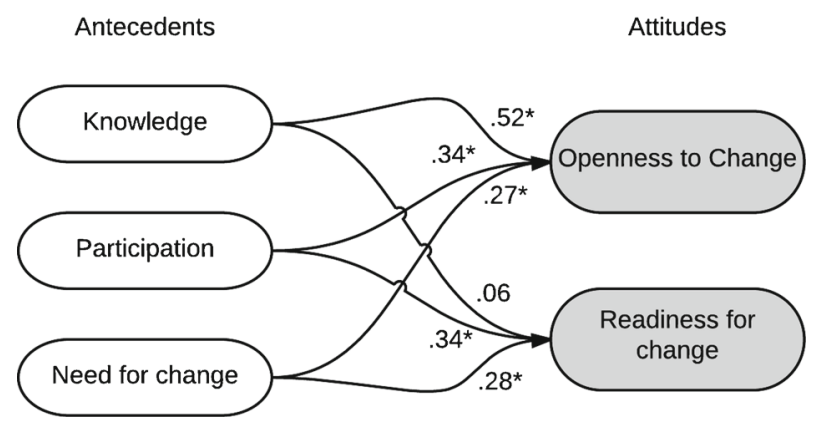

Fig. 4 Model used to predict openness to change and readiness for change. The connection line figures are the beta values from Tables 6 and 7. '*' means that the value was statistically significant at 05

to change, represent different aspects of employees' attitudes, and that lack of one concept does not simply represent the lack of another. However, worth noticing is that knowledge about the intended change outcome seems to be a vital component in openness to change, whereas it seems to be negligible in readiness for change, has not been shown before.

Moreover, on a more general level, our result adds some support to theoretical change theories, such as Rendahl's model for effective organizational change (Rendahl and Hart 1996) and Kotter's organizational change process (Kotter 1996).

Second, this study contributes by applying partially existing concepts to a previously unexplored context, i.e. software engineering. It indicates that need for change, participation and knowledge have a significant impact of software engineers' attitudes. It also provides some support for a hierarchy with respect to the three predictive concepts' degree of impact, where knowledge has a higher impact factor compared to participation (only valid for openness to change), and participation, in turn, has a higher impact factor compared to need for change.

Third and final, our findings add knowledge to the rich literature of attitudes towards organizational change by identifying and verifying two previously unexplored significant concepts, i.e. knowledge and need for change.

Taken together, results from this study provide directions for software engineering organizations to follow when aiming to increase support for proposed organizational changes. We believe that the simplicity of the proposed model from a practitioner's point-of-view has advantages. As we mentioned in the introduction, previous attitude research has identified a vast amount of concepts that affect employees' attitudes. For an organization to focus on all of them is very challenging, if not impossible. Our results help software engineering organizations to focus their efforts by identifying what significant concepts to primarily consider. Thus, organizations can raise their chances of successfully implementing change initiatives by targeting on increasing software engineers' knowledge about the change, their participation in the change process and, finally, their understanding of the need for change.

Our research provides an initial platform in an important area of software engineering, and the proposed model forms an awaited starting-point for future research. However, we acknowledge that our simplistic model cannot be considered complete. To better describe organizational life, future research should therefore focus on extending the model's complexity and also adding additional concepts.

We believe that there exist concepts unique to the software engineering context. As an example, software engineers often work together in teams and their behaviors are therefore, 
to a certain extent, controlled by the team norms. Drawing on social identity and social categorization theories, Terry et al. (2000) argue that only the attitudes supported by in-group norms predict behavior. This implies that to establish a behavior change among software engineers, management needs to analyze if the changes are aligned with the group norms. If not, they need to find ways to alter them, otherwise the team members will not behave according to the attitudes and, in practice, no organizational change will occur.

In addition, using a longitudinal study we plan to evaluate if interventions can influence the factors in the attitude model and thereby also improve on the employees' attitudes towards the change.

\subsection{Threats to Validity}

A limitation in this study was the number of questions we were allowed by the company to use in the questionnaire, which restricted the study to include five variables. We acknowledge that such a first-order ${ }^{2}$ model cannot be considered complete; rather, it is to be recognized as an initial approximation that captures the most significant effects.

Regarding the operationalization of two concepts knowledge and need for change, we recognize a threat to validity. In particular, the representativeness of the measurements for knowledge, i.e. the construct validity, is questionable. In this study, we have made the assumption that experience and knowledge together can be seen to form a psychological concept that relates to the understanding of a subject (team-based development in our case). We chose to name this psychological concept knowledge. The number of items used to define the concept was a trade-off against other constructs and the total time we could get from the industry practitioners. With only three items used to define the concept (one item was removed in the PCA), there is clearly room for improvement and refinement in the understanding of the concept.

In the factor extraction, we used principal component analysis (PCA). We recognize that this has sometimes been argued to not be a "true" method of factor analysis, but we also note that there is disagreement among statisticians in regards to the difference in result between PCA and CFA (O'brien 2007). This debate is, however, beyond the scope of the study.

Nonetheless, we recognize that there are alternatives to both PCA and CFA. In simulation conducted by Flora and Curran (2004), Robust Weighted Least Squares regression showed superior performance. Bayesian alternatives was proposed already in the early 1980's (Lee 1981) and allow for more flexible specification of models and less restrictive constraints on latent variables. For example, a recent approach of Conti et al. (2014) infers the number of factors along with other parameters and can utilize all available information without discarding measurements. In particular, Muthén and Asparouhov's (Muthén and Asparouhov 2012) Bayesian SEM approach replaces the parameter specification of exact zeros and exact equalities with approximate zeros and equalities ' and can thus better represent substantive theories without multiple, often ad hoc, model rejection and retry steps as can happen when using CFA. In future work, we can consider analyzing our data with one or more of these alternative methods.

Moreover, the choice to use multiple linear regression analysis was based on the guidelines developed by Gefen et al. (2000). According to these guidelines, second generation data analysis techniques, such as partial least squares path analysis and LISREL, require a

\footnotetext{
${ }^{2}$ The order of approximation indicates how precise an approximation is. First-order approximation is the term used for a further educated guess at an answer (Wikipedia 2015).
} 
sample size at least 10 times the number of latent variables in the model. We recognize that this is just a rule of thumb and that there is no general consensus on the appropriate method for determining adequate sample size (Westland 2006, 2010; Wolf et al. 2013). Nonetheless, with a sample size of 56 , the choice of analysis method was by no means obvious but rather a border line case and we, therefore, acknowledge that using an alternative analysis method could have been a viable option that we will consider in future work.

Finally, in this study we have made the assumption that there is a correlation between attitude and behavior, and that a positive attitude towards organizational change ultimately will lead to a successful organizational change. This assumption needs to be verified.

\section{Conclusions}

In this study, we have identified three underlying concepts with an expected significant impact on software engineers' attitudes towards organizational change, i.e. their knowledge about the intended change outcome, their understanding of the need for change, and their feelings of participation in the change process.

We have shown that the attitude concept openness to change is predicted by all three underlying concepts, while the attitude concept readiness for change is predicted by need for change and participation.

Our research provides an empirical baseline to an important area of software engineering and the result can be a starting-point for future organizational change research. In addition, the proposed model prescribes practical directions for software engineering organizations to adopt in improving employees' responses to change and, thus, increase the probability of a successful change.

Acknowledgments We acknowledge the support of Swedish Armed Forces, Swedish Defense Materiel Administration and Swedish Governmental Agency for Innovation Systems (VINNOVA) in the project 'Aligning Requirements and Verification Practices in Air Traffic Control Systems' (project number 201301199).

Open Access This article is distributed under the terms of the Creative Commons Attribution 4.0 International License (http://creativecommons.org/licenses/by/4.0/), which permits unrestricted use, distribution, and reproduction in any medium, provided you give appropriate credit to the original author(s) and the source, provide a link to the Creative Commons license, and indicate if changes were made.

\section{References}

Abdi H, Williams LJ (2010) Principal component analysis. Wiley Interdiscip Rev Comput Stat 2(4):433459

Ajzen I (1991) The theory of planned behavior. Organ Behav Hum Decis Process 50(2):179-211

Ajzen I (2001) Nature and operation of attitudes. Annu Rev Psychol 52(1):27-58

Ajzen I, Fishbein M (1977) Attitude-behavior relations: a theoretical analysis and review of empirical research. Psychol Bull 84(5):888

Angeline S, Sudha S (2015) Transformational leaders as change agents in information technology organisations. Int J Appl Eng Res 10(6):14,299-14,308. http://www.scopus.com/inward/record.url?eid=2-s2. 0-84928919924\&partnerID $=40 \& \mathrm{md} 5=13 \mathrm{f} 83305846 \mathrm{cad} 5 \mathrm{a} 66 \mathrm{a} 5 \mathrm{~b} 21 \mathrm{fa} 13 \mathrm{be} 2 \mathrm{~d} 6$.

Association AP (2015) How does apa define psychology. http://www.apa.org/support/about-apa.aspx?item=7

Baddoo N, Hall T (2004) De-motivators for software process improvement: an analysis of practitioners' views. Quality control and applied statistics 49(3):341-342

Beer M (2000) Breaking the code of change Harvard Business Press 
Beer M, Eisenstat R, Spector B (1990) Why change programs don't produce change. Harv Bus Rev 68(6):158-166

Boehm B, Turner R (2005) Management challenges to implementing agile processes in traditional development organizations. Software, ieee 22(5):30-39

Bouckenooghe D (2010) Positioning change recipients' attitudes toward change in the organizational change literature. J Appl Behav Sci 46(4):500-531

Braun V, Clarke V (2006) Using thematic analysis in psychology. Qual Res Psychol 3(2):77-101

Cao L, Mohan K, Xu P, Ramesh B (2009) A framework for adapting agile development methodologies. Eur J Inf Syst 18(4):332-343

Cestari Silva C, Goldman A (2014) Agile methods adoption on software development: a pilot review. In: Agile conference (AGILE), 2014, pp 64-65. IEEE

Chan FK, Thong JY (2009) Acceptance of agile methodologies: a critical review and conceptual framework. Decis Support Syst 46(4):803-814

Choi M. (2011) Employees' attitudes toward organizational change: a literature review. Hum Resour Manag 50(4):479-500

Cohn M, Ford D (2003) Introducing an agile process to an organization. Computer 36(6):74-78

Conboy K, Coyle S, Wang X, Pikkarainen M (2010) People over process: Key challenges in agile development. IEEE Softw 28(4):48-57

Conti G, Frühwirth-Schnatter S, Heckman JJ, Piatek R. (2014) Bayesian exploratory factor analysis. J Econ 183(1):31-57

Crano WD, Prislin R (2006) Attitudes and persuasion. Annu Rev Psychol 57:345-374

Creswell JW (2013) Research design: qualitative, quantitative, and mixed methods approaches Sage publications

Cruz SS, da Silva FQ, Monteiro CV, Santos P, Rossilei I (2011) Personality in software engineering: Preliminary findings from a systematic literature review. In: 15th annual conference on Evaluation \& assessment in software engineering (EASE 2011), pp 1-10. IET

Cruzes DS, Dyba T (2011) Recommended steps for thematic synthesis in software engineering. In: 2011 international symposium on Empirical software engineering and measurement (ESEM), pp 275-284. IEEE

Cugola G, Ghezzi C (1998) Software processes: a retrospective and a path to the future. Software Process: Improvement and Practice 4(3):101-123

Cunningham CE, Woodward CA, Shannon HS, MacIntosh J, Lendrum B, Rosenbloom D, Brown J (2002) Readiness for organizational change: a longitudinal study of workplace, psychological and behavioural correlates. J Occup Organ Psychol 75(4):377-392

D'aveni RA (2010) Hypercompetition simon and schuster

Duka D (2013) Adoption of agile methodology in software development. In: Information \& communication technology electronics \& microelectronics (MIPRO), 2013 36th international convention on IEEE, pp 426-430

Escobar-Sarmiento V, Linares-Vasquez M (2012) A model for measuring agility in small and medium software development enterprises. In: Informatica (CLEI), 2012 XXXVIII conferencia latinoamericana en IEEE, pp 1-10

Ferrie JE, Shipley MJ, Marmot MG, Stansfeld S, Smith GD (1995) Health effects of anticipation of job change and non-employment: longitudinal data from the whitehall ii study. Bmj 311(7015):1264-1269

Festinger L (1962) A theory of cognitive dissonance, vol. 2 Stanford university press

Fisbein M, Ajzen I (1975) Belief, attitude, intention and behavior: an introduction to theory and research JSTOR

Fishbin M (1972) A consideration of beliefs and their role in attitude measurement. Readings in Attitude Theory and Measurement. Hahn Wiley \& Sons, New York

Flora DB, Curran PJ (2004) An empirical evaluation of alternative methods of estimation for confirmatory factor analysis with ordinal data. Psychol Methods 9(4):466

Gandomani TJ, Zulzalil H, Ghani A, Azim A, Sultan M, Bakar A (2013) Important considerations for agile software development methods governance. Journal of Theoretical and Applied Information Technology 55(3):345-351

Gandomani TJ, Zulzalil H, Ghani AAA, Sultan ABM, Nafchi MZ (2013) Obstacles in moving to agile software development methods; at a glance. J Comput Sci 9(5):620

Gandomani TJ, Zulzalil H, Ghani AAA, Sultan ABM, Parizi RM (2015) The impact of inadequate and dysfunctional training on agile transformation process: a grounded theory study. Inf Softw Technol 57:295309

Gandomani TJ, Zulzalil H, Ghani AAA, Sultan ABM, Sharif KY (2013) Exploring key factors of pilot projects in agile transformation process using a grounded theory study. In: Information and software technologies. Springer, pp 146-158 
Gandomani TJ, Zulzalil H, Ghani AAA, Sultan ABM, Sharif KY (2014) An exploratory study on managing agile transition and adoption. In: Recent advances in information and communication technology. Springer, pp 177-188

Gandomani TJ, Zulzalil H, Ghani AAA, Sultan ABM, Sharif KY (2014) How human aspects impress agile software development transition and adoption. International Journal of Software Engineering and Its Applications 8(1):129-148

Gandomani TJ, Zulzalil H, Nafchi MZ (2014) Agile transformation: What is it about? In: Software engineering conference (mySEC), 2014 8th Malaysian, pp 240-245. IEEE

Gannon M (2013) An agile implementation of scrum. In: Aerospace conference, 2013 IEEE, pp 1-7. IEEE

Gawronski B, Creighton LA (2013) Dual-process theories. The Oxford handbook of social cognition:282312

Gefen D, Straub D, Boudreau MC (2000) Structural equation modeling and regression: Guidelines for research practice. Commun Assoc Inf Syst 4(1):7

Ghani I, Bello M (2015) Agile adoption in it organizations, vol 9

Greenwood R, Hinings CR (1996) Understanding radical organizational change: Bringing together the old and the new institutionalism. Acad Manag Rev 21(4):1022-1054

Hair JF, Black WC, Babin BJ, Anderson RE, Tatham RL (2006) Multivariate data analysis, vol 6. Pearson Prentice Hall Upper Saddle River, NJ

Hajjdiab H, Taleb AS, Ali J (2012) An industrial case study for scrum adoption. J Softw 7(1):237-242

Hayes S, Richardson I (2008) Scrum implementation using kotter's change model. In: Agile processes in software engineering and extreme programming. Springer, pp 161-171

Herbsleb JD, Goldenson DR (1996) A systematic survey of cmm experience and results. In: Proceedings of the 18th international conference on Software engineering 1996., pp 323-330. IEEE

Highsmith J, Cockburn A (2001) Agile software development: The business of innovation. Computer 34(9):120-127

Hui A (2013) Lean change: Enabling agile transformation through lean startup, kotter and kanban: An experience report. In: Agile conference (AGILE), 2013, pp 169-174. IEEE

Hutchinson J, Whittle J, Rouncefield M (2014) Model-driven engineering practices in industry: social, organizational and managerial factors that lead to success or failure. Sci Comput Program 89:144161

Iivari J, Huisman M (2007) The relationship between organizational culture and the deployment of systems development methodologies. MIS Q:35-58

Johnson BT, Eagly AH (1989) Effects of involvement on persuasion: a meta-analysis. Psychol Bull 106(2):290

JUMA EC (2014) Organizational change as a strategy for competitive advantage at practical action eastern africa. Ph.D. thesis, SCHOOL OF BUSINESS UNIVERSITY OF NAIROBI

Kautz K, Nielsen PA (2004) Understanding the implementation of software process improvement innovations in software organizations. Inf Syst J 14(1):3-22

Kim E, Ryoo S (2012) Agile adoption story from nhn. In: Computer software and applications conference (COMPSAC), 2012 IEEE 36th annual, pp 476-481. IEEE

Kitchenham B (2004) Procedures for performing systematic reviews. keele, UK. Keele University 33:2004

Kotter JP (1996) Why transformation efforts fail. J Prod Innov Manag 2(13):170

Kotter JP, Cohen DS (2002) The heart of change: Real-life stories of how people change their organizations Harvard Business Press

Kouzari E, Gerogiannis V, Stamelos I, Kakarontzas G (2015) Success factors and barriers for lightweight spi in agile development: a literature review. In: 10th International Conference on Software Engineering and Applications (ICSOFT-EA-2015), pp 151-159. doi:10.1016/S0031-8914(53)80099-6

Lavallée M, Robillard PN (2012) The impacts of software process improvement on developers: a systematic review. In: Proceedings of the 34th international conference on software engineering, pp 113-122. IEEE press

Lee SY (1981) A bayesian approach to confirmatory factor analysis. Psychometrika 46(2):153-160

Lenberg P, Feldt R, Wallgren LG (2014) Towards a behavioral software engineering. In: Proceedings of the 7th international workshop on cooperative and human aspects of software engineering, pp 48-55. ACM

Lenberg P, Feldt R, Wallgren LG (2015) Behavioral software engineering A definition and systematic literature review. Journal of Systems and Software

Lenberg P, Feldt R, Wallgren LG (2015) Human factors related challenges in software engineering-an industrial perspective. In: 2015 IEEE/ACM 8th international workshop on Cooperative and human aspects of software engineering (CHASE), pp 43-49. IEEE 
Li J, Moe NB, Dybå T (2010) Transition from a plan-driven process to scrum: a longitudinal case study on software quality. In: Proceedings of the 2010 ACM-IEEE international symposium on empirical software engineering and measurement, p 13. ACM

Little J (2003) Change your organization (for peons). In: Null, p 54. IEEE

Livermore JA (2007) Factors that impact implementing an agile software development methodology. In: Southeastcon, 2007. Proceedings. IEEE, pp 82-86. IEEE

Mathiassen L, Ngwenyama OK, Aaen I (2005) Managing change in software process improvement. Software, IEEE 22(6):84-91

Meaney M, Pung C (2008) Mckinsey global results: Creating organizational transformations. McKinsey Q. August:1-7

Meyers LS, Gamst G, Guarino AJ (2006) Applied multivariate research: Design and interpretation Sage

Miller VD, Johnson JR, Grau J (1994) Antecedents to willingness to participate in a planned organizational change Journal of Applied Communication Research

Mockus A (2010) Organizational volatility and its effects on software defects. In: Proceedings of the eighteenth ACM SIGSOFT international symposium on foundations of software engineering, pp 117-126. ACM

Muchinsky PM (1997) Psychology applied to work: An introduction to industrial and organizational psychology Thomson Brooks/Cole Publishing Co

Muthén B, Asparouhov T (2012) Bayesian structural equation modeling: a more flexible representation of substantive theory. Psychol Methods 17(3):313

Nelson HJ, Armstrong DJ, Nelson KM (2009) Patterns of transition: The shift from traditional to objectoriented development. J Manag Inf Syst 25(4):271-298

Nerur S, Mahapatra R, Mangalaraj G (2005) Challenges of migrating to agile methodologies. Commun ACM 48(5):72-78

Niazi M, Wilson D, Zowghi D (2006) Critical success factors for software process improvement implementation: an empirical study. Software Process: Improvement and Practice 11(2):193-211

Nikitina N, Kajko-Mattsson M (2011) Developer-driven big-bang process transition from scrum to kanban. In: Proceedings of the 2011 international conference on software and systems process, pp 159-168. ACM

Nikitina N, Kajko-Mattsson M, Stråle M (2012) From scrum to scrumban: A case study of a process transition. In: Proceedings of the international conference on software and system process, pp 140-149. IEEE press

Noordeloos R, Manteli C, Van Vliet H (2012) From rup to scrum in global software development: a case study. In: 2012 IEEE seventh international conference on Global software engineering (ICGSE), pp 31-40. IEEE

Nunnally JC, Bernstein IH, Berge JMT (1967) Psychometric theory, vol. 226 McGraw-Hill New York

O'brien RM (2007) A caution regarding rules of thumb for variance inflation factors. Qual Quant 41(5):673690

Olsson HH, Alahyari H, Bosch J (2012) Climbing the "stairway to heaven" - a mulitiple-case study exploring barriers in the transition from agile development towards continuous deployment of software. In: Proceedings - 38th EUROMICRO conference on software engineering and advanced applications, SEAA 2012, pp 392-399

Oreg S (2006) Personality, context, and resistance to organizational change. Eur J Work Organ Psy 15(1):73101

Oreg S, Vakola M, Armenakis A (2011) Change recipients' reactions to organizational change a 60-year review of quantitative studies. J Appl Behav Sci 47(4):461-524

Osborne JW, Costello AB (2004) Sample size and subject to item ratio in principal components analysis. Practical assessment, research \& evaluation 9(11):8

Parizi RM, Gandomani TJ, Nafchi MZ (2014) Hidden facilitators of agile transition: Agile coaches and agile champions. In: Software engineering conference (mySEC), 2014 8th Malaysian, pp 246-250. IEEE

Pettigrew AM, Woodman RW, Cameron KS (2001) Studying organizational change and development: Challenges for future research. Acad Manag J 44(4):697-713

Piderit SK (2000) Rethinking resistance and recognizing ambivalence: a multidimensional view of attitudes toward an organizational change. Acad Manag Rev 25(4):783-794

Piri A, Niinimäki T, Lassenius C (2012) Fear and distrust in global software engineering projects. Journal of Software: Evolution and Process 24(2):185-205

Platt DS (2007) Why Software Sucks-and what You Can Do about it Addison-Wesley Professional

Prochaska JO, Velicer WF, Rossi JS, Goldstein MG, Marcus BH, Rakowski W, Fiore C, Harlow LL, Redding CA, Rosenbloom D et al (1994) Stages of change and decisional balance for 12 problem behaviors. Health Psychol 13(1):39 
Prokhorenko S (2012) Skiing and boxing: Coaching product and enterprise teams. In: Agile conference (AGILE), 2012, pp 191-196. IEEE

Qumer A, Henderson-Sellers B (2008) A framework to support the evaluation, adoption and improvement of agile methods in practice. J Syst Softw 81(11):1899-1919

Rafferty AE, Jimmieson NL, Armenakis AA (2013) Change readiness a multilevel review. J Manag 39:110 135

Rendahl JE, Hart H (1996) Att förändra och leda morgondagens arbete VIS Strategi

Robey D, Ross JW, Boudreau MC (2002) Learning to implement enterprise systems: an exploratory study of the dialectics of change. J Manag Inf Syst 19(1):17-46

Rodríguez P, Mikkonen K, Kuvaja P, Oivo M, Garbajosa J (2013) Building lean thinking in a telecom software development organization: strengths and challenges. In: Proceedings of the 2013 international conference on software and system process, pp 98-107. ACM

Rosenberg S (2015) Organizational culture aspects of an agile transformation. In: Agile processes, in software engineering, and extreme programming. Springer, pp 279-286

Sapnas KG, Zeller RA (2002) Minimizing sample size when using exploratory factor analysis for measurement. J Nurs Meas 10(2):135-154

Sato S, Washizaki H, Fukazawa Y, Inoue S, Ono H, Hanai Y, Yamamoto M (2013) Effects of organizational changes on product metrics and defects. In: Software engineering conference (APSEC, 2013 20th AsiaPacific, vol. 1, pp 132-139. IEEE

Savolainen J, Kuusela J, Vilavaara A (2010) Transition to agile development-rediscovery of important requirements engineering practices. In: Requirements engineering conference (RE), 2010 18th IEEE international, pp 289-294. IEEE

Schatz B, Abdelshafi I (2005) Primavera gets agile: a successful transition to agile development. IEEE Softw 22(3):36-42

Seffernick TR (2007) Enabling agile in a large organization our journey down the yellow brick road. In: Null, pp 200-206. IEEE

Serour M, Henderson-Sellers B (2005) Resistance to adoption of an oo software engineering process: an empirical study University of technology, sydney, Australia. European and mediterranean conference on information systems (EMCIS)-2005

Serour M, Younessi H (2006) Towards method engineering for agile software development: Theory and practice. In: Proceedings of the IBIMA 2006 conference on CD,"Managing Information in the Digital Economy: Issues \& Solutions"(ed., Khalid S., Soliman), ISBN: 0-9753393-5-4, Bonn, Germany

Serour MK, Winder D (2007) Radar: A model for it organizational change four Australian case studies on the adoption and diffusion of method engineering. In: European, mediterranean and middle eastern conference on information systems. Polytechnic university of valencia, Spain

Smits H, Rilliet K (2011) Agile experience report: Transition and complexity at cisco voice technology group. In: Agile conference (AGILE), 2011, pp 274-278. IEEE

Streiner DL (2003) Starting at the beginning: an introduction to coefficient alpha and internal consistency. J Pers Assess 80(1):99-103

ten Have S, ten Have W, Huijsmans AB, Otto M (2016) Reconsidering change management: Applying Evidence-Based insights in change management practice routledge

Terry DJ, Hogg MA, McKimmie BM (2000) Attitude-behaviour relations: The role of in-group norms and mode of behavioural decision-making. Br J Soc Psychol 39:337

Thomas R, Sargent LD, Hardy C (2011) Managing organizational change: Negotiating meaning and powerresistance relations. Organ Sci 22(1):22-41

Viswanathan M (2005) Measurement error and research design Sage

Wanberg CR, Banas JT (2000) Predictors and outcomes of openness to changes in a reorganizing workplace. J Appl Psychol 85(1):132

Westland JC (2006) Structural equation models springer international publishing

Westland JC (2010) Lower bounds on sample size in structural equation modeling. Electron Commer Res Appl 9(6):476-487

Wikipedia (2015) Orders of approximation wikipedia, the free encyclopedia. https://en.wikipedia.org/w/ index.php? [Online; accessed 13-December-2015]

Wilson TD, Lindsey S, Schooler TY (2000) A model of dual attitudes. Psychol Rev 107(1):101

Wolf EJ, Harrington KM, Clark SL, Miller MW (2013) Sample size requirements for structural equation models an evaluation of power, bias, and solution propriety. Educ Psychol Meas 73(6):913-934

Woodward CA, Shannon HS, Cunningham C, McIntosh J, Lendrum B, Rosenbloom D, Brown J (1999) The impact of re-engineering and other cost reduction strategies on the staff of a large teaching hospital: a longitudinal study. Med Care 37(6):556-569

Yong AG, Pearce S (2013) A beginner's guide to factor analysis: Focusing on exploratory factor analysis. Tutor Quant Methods Psychol 9(2):79-94 


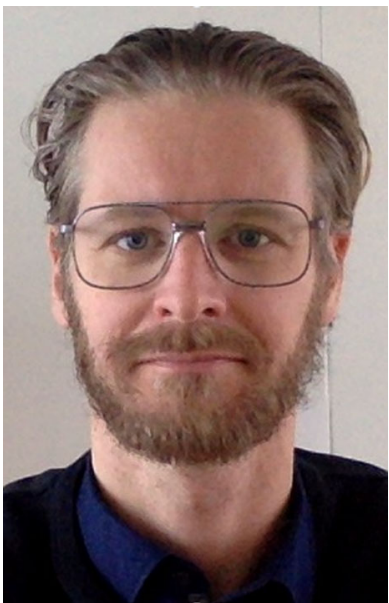

Per Lenberg is an industrial $\mathrm{PhD}$ student in Software Engineering at Chalmers University of Technology in Gothenburg, Sweden. He has a M. Sc of Computer Science and Engineering from that same university and a Bachelors degree in Psychology from the University of Gothenburg. He has worked for more than 10 years in the software industry.

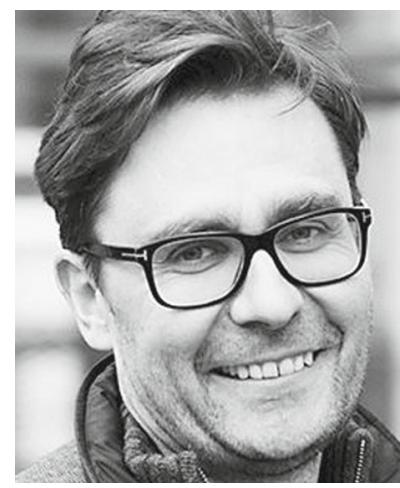

Robert Feldt is a professor of software engineering at Chalmers University of Technology, Sweden and at Blekinge Institute of Technology, Sweden. He has also worked as an IT and software consultant for more than 20 years. His research interests include human-centered software engineering, software testing and verification and validation, automated software engineering, requirements engineering, and user experience. He has published more than 90 scientific papers. Most of his research is empirical and conducted in close collaboration with industry partners. He received a Ph.D. (Techn. Dr.) in computer engineering from Chalmers University of Technology in 2002. 


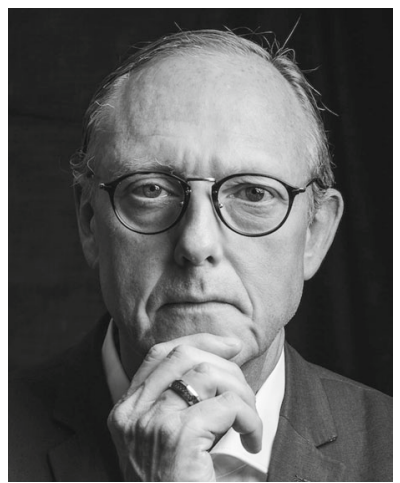

Lars Göran Wallgren Tengberg has a PhD in Psychology from the University of Gothenburg, Sweden. His focus is on psychological issues in the IT industry, in particular motivation, and has extensive experience both as a consultant and in different positions of software and IT companies. 